\title{
ORIGEM E EVOLUÇÃO TECTÔNICA DA BACIA SANFRANCISCANA
}

\author{
JOSÉ ELOI GUIMARÃES CAMPOS* \& MARCEL AUGUSTE DARDENNE*
}

\begin{abstract}
ORIGIN AND TECTONIC EVOLUTION OF THE SANFRANCISCANA BASIN This paper presents data about the origin and tectonic evolution of the Phanerozoic cover of the São Francisco Craton, defmed as the Sanfranciscana Basin. The tectonic compartmentation allowed the subdivision in the Abaeté (south portion) and the Urucuia sub-basins (middle-north portion). The stratigraphy and sedimentology of the Phanerozoic successions are as follows: Santa Fé Group (Permo-Carboniferous) - subdivided into the Floresta and Tabuleiro formations. Areado Group (Early Cretaceous) comprising the Abaeté, Quiricó and Três Barras forraations. Mata da Corda Group (Late Cretaceous) composed by the Patos and Capacete formations. Urucuia Group (Late Cretaceous) composed by the Posse and Serra das Araras formations. Chapadão Formation (Cenozoic) represents the sandy, unconsolidated, recent covers of talus, residual or alluvium origin.

Paleozoic epyrogenesis characterized the onset of tectonism in the Sanfranciscana Basin. During the Mesozoic the basin has undergone tectonic reactivations finishing with neotectonic activity in Cenozoic times. The origin of the basin, as well as its tectonic evolution had been controlled by the São Francisco Craton marginal fold-and-thrust belts (Brasilia and Araçuaí belts), by the South Atlantic opening (rift phase) and by transform oceanic fractures (drift phase).
\end{abstract}

Keywords: Sanfranciscana Basin, tectonic evolution, Gondwana drift.

RESUMO Este artigo apresenta dados sobre a origem e evolução tectônica da Cobertura Fanerozóica do Cráton do São Francisco denominada de Bacia Sanfranciscana. Diferenças tectônicas, estratigráficas e ambientais permitem a divisão da bacia em dois compartimentos denominados de Sub-Bacia Abaeté e Sub-Bacia Urucuia. A estratigrafia das sucessões fanerozóicas inclui as seguintes unidades: Grupo Santa Fé (Permo-Carbonífero) composto pelas formações Floresta e Tabuleiro; Grupo Areado (Eocretáceo) constituído pelas formações Abaeté, Quiricó e Três Barras; Grupo Mata da Corda (Neocretáceo) composto pelas formaçôes Patos e Capacete; Grupo Urucuia (Neocretáceo), sub-dividido nas formações Posse e Serra das Araras e Formação Chapadão (Cenozóico), representando as coberturas arenosas inconsolidadas recentes, de caráter eluvio-coluvionar ou aluvionar. A bacia foi iniciada a partir de uma tectônica de rearranjos isostáticos no Paleozóico, com reativacõos no Mezosóico e atividade neotectônica no Cenozóico. Sua origem e evolução tectônica foi controlada pelas faixas marginais do Craton do São Francisco (faixas Brasília e Araçuaí) e pela abertura do Attântico Sul, durante as fases pré- a pós-rifte e por fraturas transformantes na fase de mar aberto.

Palavras-chaves: Bacia Sanfranciscana, evolução tectônica, ruptura gonduânica.

INTRODUÇ̃̃O Estudos tectônicos, objetivando o entendimento da origem e evolução estrutural da Bacia Sanfranciscana, são raros. Alguns aspectos de interesse local são geralmente referidos nos trabalhos de estratigrafia e sedimentologia. Apenas os artigos de Hasui \& Haralyi (1991) e Sawasato (1995) discutem a tectônica formadora da bacia, enfatizando a Sub-Bacia Abaeté

A forma geral da bacia, alongada segundo a direção nortesul (Fig. 1), e o seu paralelismo com o aulacógeno do Recôncavo-Tucano-Jatobá sugerem tratar-se de um rifte relacionado à evolução da margem continental brasileira.

Entretanto, as características gerais da bacia mostram uma tectônica pouco pronunciada, contrariando a hipótese de evolução por rifteamento continental sugerida pela sua disposição geral norte-sul. $\mathrm{O}$ conhecimento detalhado dos aspectos tectônicos da bacia permite a proposição de um modelo de preenchimento de calha tipo sag, ou seja, uma ampla bacia intracontinental com pequena subsidência, apenas localmente afetada por incipientes processos tafrogênicos. Os principais argumentos que corroboram o modelo de bacia tipo sag, compreendem:

1 Razão comprimento/largura da bacia da ordem de 3, em contraste com riftes cuja razão é geralmente superior a 5 . No rifte do Takutu esta razão é superior a 6 e no Recôncavo-Tucano-Jatobá em torno de 5;

2 Espessura sedimentar reduzida (inferior a 500m nas porções mais espessas). As bacias do Takutu e Recôncavo apresentam espessuras superiores a $7.000 \mathrm{~m}$;

3 Ausência de compartimentação por falhas de bordas, características dos riftes continentais;
4 Ausência de conglomerados de bordas falhadas e as constantes estruturas de transferência e acomodação que frequentemente invertem a polaridade dos rifts, mudando as bordas de falhas para bordas flexurais;

5 Ausência dos elementos estruturais típicos de rifts tais como, antiformes, rotação de blocos, falhas de alívio, falhas inversas, etc. como os descritos por Aragão \& Perano (1994) e Aragão (1994), respectivamente no sistema de riftes Tucano-Jatobá e na Bacia do Recôncavo;

6 Ausência de recorrência de pulsos de rejeito normal que causam intensa deformação, descontinuidades e até discordâncias importantes no registro sedimentar;

7 Ausência de depocentros junto às falhas de borda e de altos de embasamento junto às zonas de tranferências.

8 Padrão de contrastes gravimétricos distinto dos casos de rifts típicos, com baixos valores das anomalias bouguer ao longo das calhas sedimentares, refletindo uma espessa coluna sedimentar.

Embora a maior parte da evolução da bacia seja ligada à Margem Continental Brasileira, ativa principalmente entre o Aptiano e o Maastrichtiano, não existe uma correlação significativa entre as fases tectônicas sin-rifte, rifte e pós-rifte de Chang et al. (1990).

Desde o Paleozóico até o recente, vários estágios tectônicos controlados por períodos de relativa estabilidade, rápidas inversões nos campos de tensão, extensivos/compressivos, e movimentos verticais de compensação isostática marcaram a génese e evolução da bacia. 


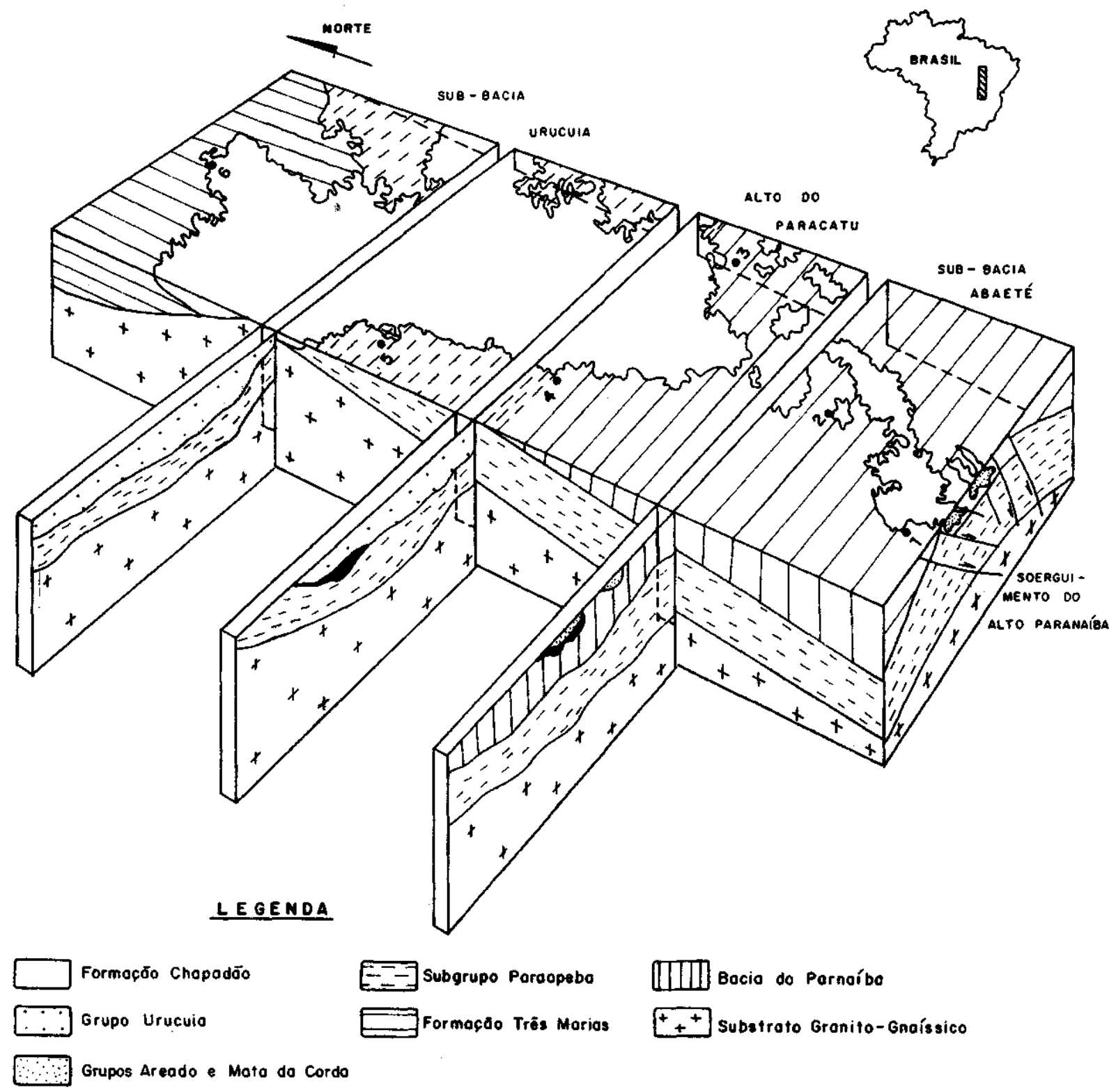

Figura 1 - Bloco diagrama mostrando a situação da Bacia Sanfranciscana e a distribuição regional de seu embasamento. Localidades: 1 - Patos de Minas/MG; 2 - Canabrava/MG; 3 -Pirapora/MG; 4 - Posse/GO; 5 - São Domingos/GO e 6 -Gilbués/PI. Figure 1 - Block-diagram showing the situation of the Sanfranciscana Basin and the distribution of the regional basement. Localities: 1 - Patos de Minas/MG; 2 -Canabrava/MG; 3 - Pirapora/MG; 4 - Posse/GO; 5 - São Domingos/GO e 6 - Gilbués/PI.

Tectonicamente, importantes diferenças marcam o desenvolvimento das duas sub-bacias. Estas diferenças são observadas tanto na intensidade dos campos de stress quanto na ausência de um evento na Sub-Bacia Urucuia, como será descrito nos estágios tectônicos.

Seis estágios evolutivos distintos ou parcialmente sincrônicos foram considerados para um melhor entendimento da história tectônica da Bacia Sanfranciscana. Para os estudos tectônicos foram importantes:

- os diversos conjuntos de estruturas do embasamento e das sucessões fanerozóicas;

- o padrão de sedimentação, incluindo os sistemas deposicionais e paleocorrentes associadas;

- o contexto global de separação gonduânica durante o Mesozóico.

A estratigrafia integrada da bacia é caracterizada por cinco sucessões separadas por importantes superficies de erosão. A unidade mais antiga, denominada de Grupo Santa Fé, é posicionada no Permo-Carbonífero, representando um conjunto de sedimentos glaciogênicos dividido nas formações Floresta e Tabuleiro. A sucessão de idade paleocretácea é designada de Grupo Areado a qual se subdivide nas formações Abaeté, Quiricó e Três Barras que representam uma sucessão de sedimentos fluviais, lacustres, eólicos e deltaicos. Restrito ao segmento sul da Bacia ocorre o Grupo Mata da Corda dividido nas formações Patos e Capacete, o qual consiste de um conjunto de lavas e piroclásticas e sedimentos epiclásticos de idade neocretácea. Também atribuídos ao Neocretáceo, ocorrem arenitos de sistemas desérticos do Grupo Urucuia que se distribuem principalmente na porção norte da bacia. Recobrindo todas as unidades citadas ocorre a Formação Chapadão que compreende coberturas cenozóicas aluvionares, coluvionares e eluvionares. 
O embasamento da Bacia Sanfranciscana é representado na maior extensão da bacia pelo Grupo Bambuí, além de rochas sedimentares paleozóicas no extremo norte da bacia, rochas metassedimentares dos grupos Araxá e Canastra no extremo sul, e restritas faixas granito-gnássicas no meio-norte da bacia.

COMPARTIMENTAÇÃO DA BACIA O atual grau de conhecimento da bacia permite sua divisão nas sub-bacias: Abaeté, a sul, e Urucuia, no centro-norte. A separação entre as duas sub-bacias se faz na região do Alto do Paracatu, na porção meridional da bacia.

A Bacia Sanfranciscana, como um todo, é limitada a sul com a Bacia do Paraná pela Flexura de Goiânia/Soerguimento do Alto Paranaíba. A norte, limita-se com a Bacia do Parnaíba através do Arco do São Francisco. Os limites ocidental e oriental são respectivamente marcados pelas bordas externas das faixas Brasília e Araçuaí/Espinhaço Setentrional (Fig. 2).

Limites longitudinais Os limites longitudinais da bacia são paralelos aos das faixas Brasília e Araçuá/Espinhaço Setentrional, que representam extensos thmsts-and-folded belts brasilianos. A distância entre as margens atuais da bacia e as faixas dobradas é de mais de $150 \mathrm{~km}$. Contudo, a presença de testemunhos isolados das coberturas fanerozóicas nas regiões de Montes Claros/MG (borda leste) e Buritis/MG (borda oeste) mostram que a bacia era mais larga do que atualmente observado. Apenas na borda oeste da Sub-Bacia Abaeté, em seu segmento sul, os limites da bacia alcançam os lineamentos da Faixa Brasília.

Datações radiométricas posicionam a maior parte da evolução destas faixas no Neoproterozóico, com pico de metamorfismo em torno de $600 \mathrm{Ma}$, e com granitogênese de idade entre 800 e 450 Ma.

Estudos regionais mostram que a deformação nas faixas é gradativamente atenuada da porção interna para a porção externa. Assim, os empurrões predominam nas porções internas, enquanto falhas de empurrão de alto ângulo e falhas inversas são comuns na externa junto à transição para o cráton (Oliveira et al. 1989, Magalhães et al 1989, Alkimin et al 1989).

Arco do Alto Paranaíba Trata-se de feição tectônica/morfológica reconhecida por vários autores entre os quais (Costa 1963, Hasui 1968, Sad \& Torres, 1968 e Sad 1970). A estrutura é consensualmente aceita como um alto de embasamento, que expõe rochas proterozóicas e separa as bacias do Paraná e Sanfranciscana.

Esta estrutura funcionou como um alto desde os tempos mesoproterozóicos, quando influenciou a sedimentação das formações Canastra e Ibiá. No Paleozóico funcionou como barreira à sedimentação da Bacia do Paraná, tendo sempre marcado o limite NE daquela bacia. A partir do Meso/Neocretáceo, esta estrutura sofreu uma reativação positiva denominada soerguimento do Alto Paranaíba. Os efeitos desta reativação na sedimentação cretácea superior foram modelados por Hasui \& Haralyi (1991) com base em argumentos lito-estratigráficos e geofísicos (gravimétricos e magnetométricos).

O período de atividade deste soerguimento pode ser inferido a partir do início das intrusões dos corpos alcalinos mais antigos, que certamente foram originados a partir das anomalias mantélicas causadas pelo uplift crustal. Segundo Bizzi et al (1991) e Bizzi et al (1993), existem dois grupos de idades para as rochas alcalinas (de filiação kimberlitóide e carbonatíticas) do Triângulo Mineiro. Os referidos autores apresentam idades Rb-Sr em flogopitas que variam de 117 a $119 \mathrm{Ma}$ (mais antigas) e de 87 a $83 \mathrm{Ma}$ (mais jovens), devendo o início do soerguimento coincidir ou ser pouco mais antigo que o grupo de intrusões mais antigas, ou seja Eoaptiano.

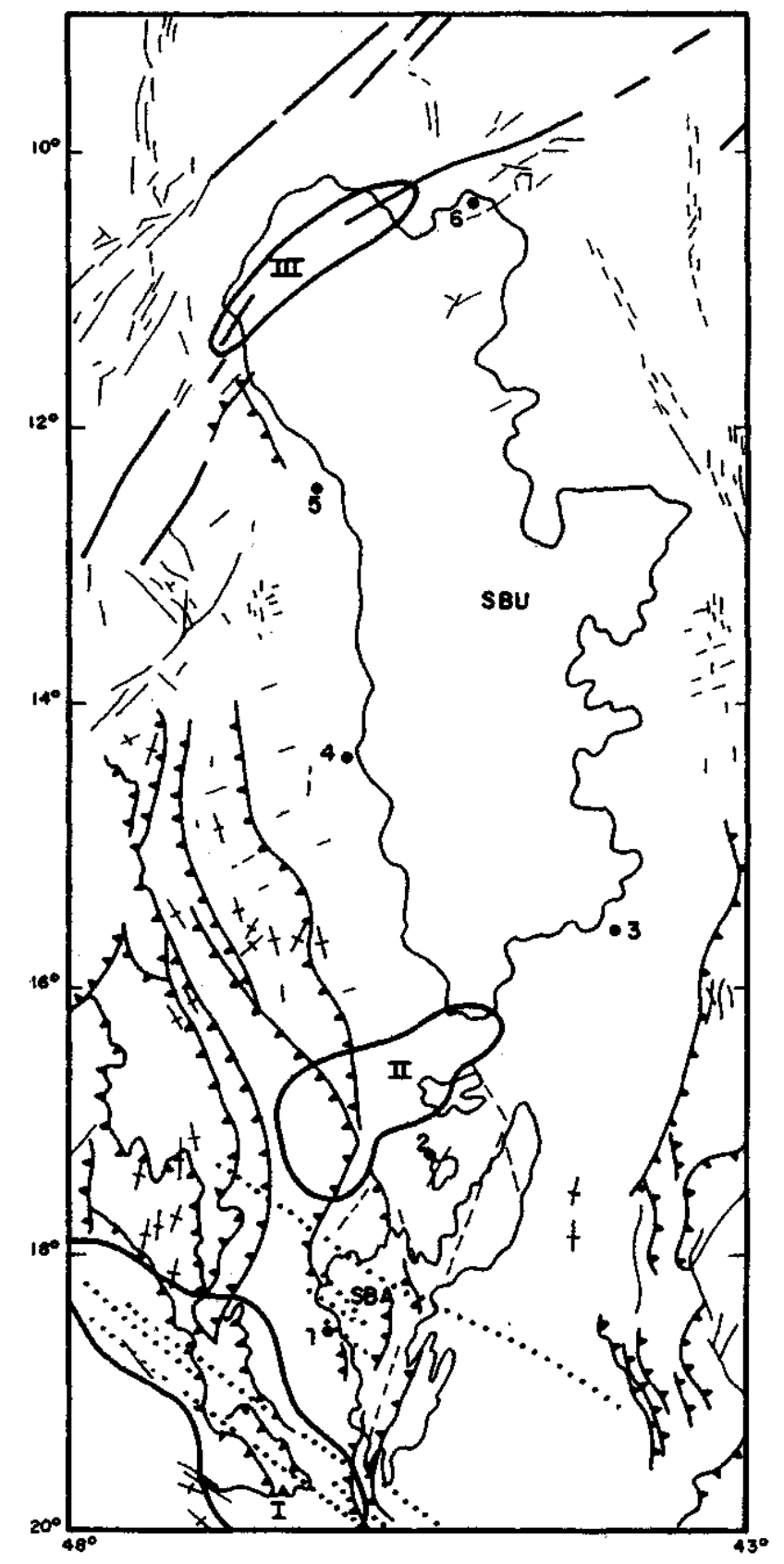

Figura 2 - Mapa das principais feições estruturais existentes no substrato da Bacia Sanfranciscana, SBA -Sub-Bacia Abaete. SBU - Sub-Bacia Urucuia. I - Arco do Alto Paranaiba. II - Alto do Paracatu. III - Arco do São Francisco. Traços dentados representam grandes planos de empurrões e falhas inversas, traços contínuos representam falhas/fraturas regionais $e$ os traços pontilhados representam anomalias geofísicas. Informações extraídas de Shobbenhaus et al 1984, cartas geológicas ao milionésimo e imagens de satélite. Localidades: l-Patos de Minas/MG; 2 -Canabrava/MG; 3 - Piraporal $M G ; 4$ - Posse/GO; 5 - São Domingos/GO e 6 - Gilbués/PI. Figure 2 - Map of the main structural features observed in the Sanfranciscana Basin basement. SBA - Abaeté Sub-Basin. SBU - Urucuia Sub-Basin. I - Alto do Paranaíba Arch. II -Paracatu High. III. São Francisco Arch. Serrated traces indicate inverse fault planes, continous traces indicate regional faults/ fractures and the dotted traces indicate geophysical anomaly. Information from Schobbenhaus et al. 1984, geological sheets and sate liteimages. Localities: 1 -Patos de Minas/MG; 2 - Canabrava/MG; 3 - Pirapora/MG; 4 -Posse/GO; 5 - São Domingos/GO e 6 - Gilbués/PI. 
As características químicas e isotópicas do magmatismo e a ausência de estruturas rúpteis associadas contribuem para considerar este soerguimento como o resultado de um mega domeamento, provocado por aquecimento mantélico, possivelmente relacionado a plumas no manto superior em profundidades superiores a $200 \mathrm{~km}$.

$\mathrm{Na}$ região do arco, o embasamento é composto pelos metassedimentos dos grupos Araxá, Canastra e Bambuí, cujos contatos são marcados por falhas de empurrão da tectônica Brasiliana de idade neoproterozóica.

Alto do Paracatu É representado por uma elevação regional do embasamento. A magnitude desta estrutura é muito menor que a registrada para o Arco do Alto Paranaíba. Contudo foi responsável pela segmentação da bacia em duas sub-bacias, as quais apresentam diferenças significativas em relação a sua evolução.

Esta estrutura foi identificada a partir das diferenças de altitude observadas no contato do Grupo Bambuí com a cobertura fanerozóica, de dados gravimétricos, das variações de espessuras da sucessão sedimentar e das feições geomorfológicas:

- As cotas do contato entre a Formação Três Marias e as unidades basais da bacia mostram elevação sistemática em direção ao vale do Rio Paracatu, sendo superiores a 700m na porção mediana da bacia. Nas bordas da Sub-Bacia Urucuia este contato ocorre em geral em volta da cota de $600 \mathrm{~m}$.

- A espessura de toda a seção fanerozóica é da ordem de 400 a 500m nas depressões de Abaeté e Urucuia, sendo na região do Alto do Paracatu não superior a 200m.

- Os dados gravimétricos de Lesquer et al. (1981) e Ussami \& Sá (1993), apesar da escala regional, mostram um aumento relativo das anomalias bouguer, que pode materializar este arqueamento crustal.

- O aspecto geomorfológico da região, representando a porção da bacia com maior grau de exposição do embasamento (parte descontínua da cobertura), também auxilia na determinação desta feição estrutural.

A origem deste alto pode estar relacionada a mecanismos de reequilíbrios flexurais da litosfera em resposta a sobrecarga lateral associada à tectônica Brasiliana (Faixas Araçuaí e Brasília). Esta estrutura deve apresentar, em escala reduzida, uma evolução similar à do Alto de Sete Lagoas modelado por D'Arrigo \& Alkimin (1995).

Arco de São Francisco Identificado por Martins et al. (1993), representa um divisor entre a porção sul da Bacia do Parnaíba e o segmento norte da Bacia Sanfranciscana. Hasui et al. (1991), estudando a borda sul da Bacia do Parnaíba, também fazem referência a esta estrutura como um bloco alto que separa as duas bacias.

Não existem estudos específicos que possibilitem a determinação dos limites e proporções deste arco. Porém a continuidade dos estudos geofísicos realizados pela PETROBRÁS SÁ, para fins de reconhecimento da estruturação da Bacia do São Francisco, sem dúvida auxiliará no detalhamento desta feição do embasamento.

ESTÁGIO TECTÔNICO PALEOZÓICO Corresponde a fase evolutiva da bacia durante a qual se acumularam os sedimentos glaciogênicos neopaleozóicos. É considerada a fase de atividade tectônica pouco pronunciada da bacia onde a calha sedimentar foi gerada por uma depressão relativa entre duas cadeias de montanhas em fase de denudação.

A movimentação vertical seria de pequena amplitude, sendo consequência de rearranjos isostáticos e flexurais e de uma pequena subsidência térmica originada pelo lento resfriamento do núcleo cratônico. É importante salientar que o cráton se comportava como uma placa única, somente afetada pelas pequenas descontinuidades maracadas pelos fraturamentos ligados à fase rúptil da tectônica Brasiliana, mostrando que não existiam grandes lineamentos ou zonas de suturas nas porções internas do cráton.

A relativa estabilidade tectônica, que prevaleceu durante o Paleozóico, coincidiu com o período de estabilização do continente Gonduana. Sabendo-se que não existem registros de magmatismo, como a presença de extensos corpos intrusivos no interior do Cráton do São Francisco, não se pode considerar uma significativa subsidência térmica para a formação da depressão inicial da bacia. Este fato, associado à ausência de importantes suturas no interior do cráton e à ausência de uma deformação penetrativa em grandes áreas do substrato da bacia, pode explicar porque a bacia Sanfranciscana não experimentou uma evolução similar às das grandes bacias paleozóicas como as do Paraná e Parnaíba.

A atenuação dos esforços compressivos nas fases finais da orogênese brasiliana (período de descompressão do orógeno) também deve ter contribuído com uma pequena subsidência do conjunto para a formação da calha (proto-bacia) que receberia os sedimentos paleozóicos da Bacia Sanfranciscana.

Estudos geofísicos (sísmica de reflexão) preliminares na região norte da bacia, aproximadamente ao longo do paralelo $12^{\circ}$, indicam a presença de um rifte na calha central da Sub-Bacia Urucuia (Lemoel, inf. verbal, 1994). Ao que tudo indica, esta estruturação deve ser mais antiga e está ligada à evolução inicial do extremo sul da Bacia do Parnaíba, cujos sedimentos paleozóicos integram o embasamento deste setor da Bacia Sanfranciscana. Uma fase similar é proposta por Zálan et al. (1990) para a deposição da seção neo-ordoviciana da Bacia do Paraná (Formação Rio Ivaí).

Como não ocorreu uma importante fase de subsidência mecânica ou térmica, os sedimentos acumulados neste período, representados pelo Grupo Santa Fé, apresentam baixo potencial de preservação, sendo apenas encontrados atualmente em paleodepressões do embasamento.

\section{ESTÁGIO TECTÔNICO NEOPALEOZÓICO -}

EOMESOZÓICO Também corresponde a uma etapa de relativa estabilização tectônica, sendo marcada por apresentar uma importante fase de movimentação epirogênica, seguida de intensa erosão da sucessão depositada no Carbonífero e Permiano Inferior.

O movimento epirogênico positivo ocorreu com o término da glaciação neopaleozóica, devido ao reequilíbrio isostático após a remoção da carga das capas de gelo. Estimativas com base nas espessuras erodidas dos sedimentos dos grupos Bambuí e Santa Fé indicam que o soerguimento alcançou 150 a 200.metros na porção setentrional da bacia e foi progressivamente diminuindo para sul. Esta variação explica satisfatoriamente a distribuição do embasamento, expondo unidades do Grupo Bambuí gradativamente mais basais, inclusive com a presença de rochas de embasamento granito-gnáissico para norte.

Os soerguimentos isostáticos pós-glaciais são consideráveis, sendo que, nos períodos logo após a migração das extensas e espessas geleiras, elevações de 6 a $8 \mathrm{~mm}$ por ano são reportadas próximo aos centros glaciais e de 2 a $3 \mathrm{~mm}$ por ano nas regiões peri-glaciais (Balling, 1980 e Vanicek \& Nagy 1980 in Brown \& Reilinger 1986) (ver Fig. 3).

Estudos de paleocorrentes mostraram que os centros glaciais se encontravam a NNE, região da bacia que sofreu maior soerguimento. Como não existiu um mecanismo de subsidência eficaz (e.g. reativação de falhamentos), a erosão e retrabalhamento da sucessão paleozóica foi responsável pela maior descontinuidade sedimentar observada na bacia. $\mathrm{O}$ soerguimento deve ter sido cada vez menor rumo a Sub-Bacia Abaeté onde as geleiras apresentavam volumes menores. 
O soerguimento generalizado, que se iniciou logo após a remoção das capas de gelo, favoreceu a ocorrência de fácies glaciais ressedimentadas, comumente observadas em todas as localidades onde os sedimentos glaciais estão preservados.

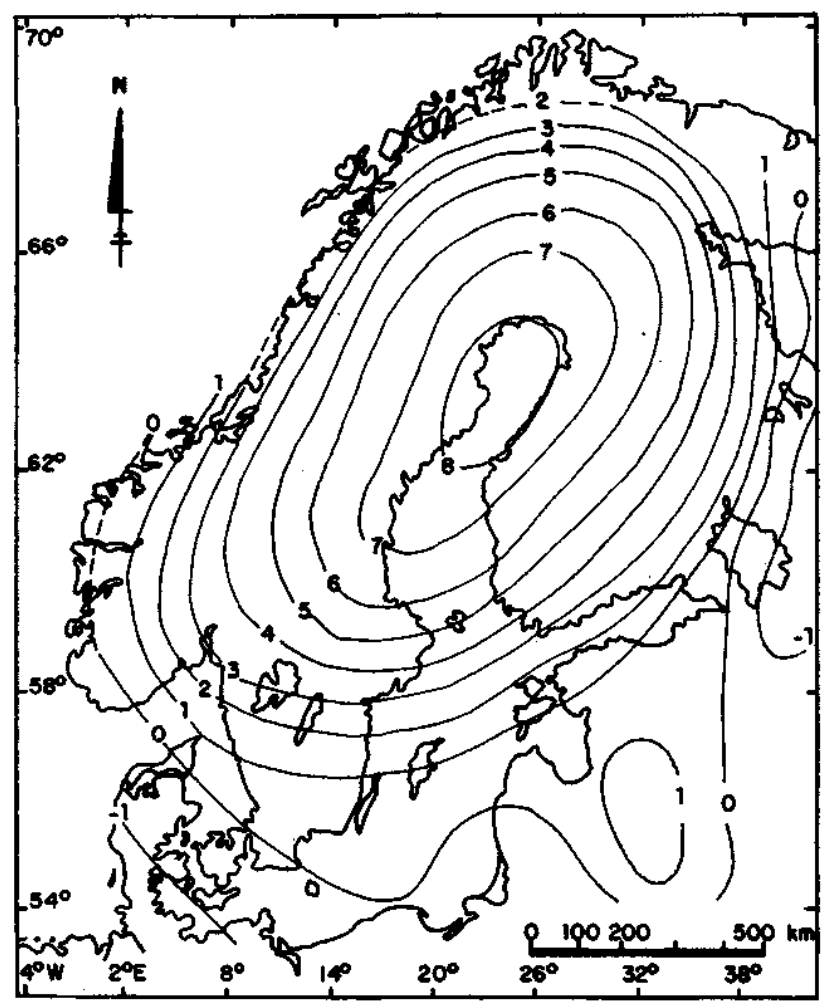

Figura 3 - Reequilíbrio isostático pós-glacial da Fenoscândia. Contornos representam o soerguimento em milímetros por ano, medido por nivelamento preciso (reproduzido de Balling, 1980 in Brown \& Reilinger, 1986). Figure 3 - Post-glacial isostatic uplift of Fennoscandia. Contours indicate the uplift in millimeters per year, measured by precise leveling (reprinted from Balling, 1980 in Brown \& Reilinger, 1986).

ESTÁGIO TECTÔNICO BARREMIANO - APTIANO (Eocretáceo) Essa etapa coincide com a fase extensiva principal da abertura do Atlântico Sul. Neste estágio todo o interior das placas sul americana e sul africana apresentavam um padrão de tensões extensivas, isto porque toda a placa litosférica submetida a rifteamento ativo sofre extensão até a total abertura e evolução para margem passiva. Gibbs (1984) mostra como localmente pode ocorrer concentração de tensões nas placas submetidas à extensão, podendo gerar inclusive bacias tipo $\mathrm{S}$ AG adjacentes a riftes que evoluíram para margem passiva.

No caso da Bacia Sanfranciscana, a distribuição dos esforços se deu de forma análoga à da margem sul-americana, com valores de extensão $p$ progressivamente maiores de sul para norte. Chang \& Kowsmann (1991) mostram que houve uma diferença de $14 \mathrm{Ma}$ entre a geração do assoalho oceânico (anomalia M4) a norte e a sul da cadeia São Paulo - Walvis, indicando maior abertura a sul e consequentemente maiores valores de extensão. Este dado foi previamente determinado por Asmus \& Porto (1980), corroborando assim esta feição que explica porque a porção sul da bacia foi submetida a maiores valores de extensão.
A magnitude do fator de estiramento $\left(\beta=\mathrm{L}_{\mathrm{f}} / \mathrm{L}_{\mathrm{i}} ; \mathrm{L}_{\mathrm{f}}=\right.$ comprimento final e $\mathrm{L}_{\mathrm{i}}=$ comprimento inicial) pode ser calculada: 1 - a partir do somatório dos blocos basculados em perfis sísmicos, 2 - em função das relações angulares entre os blocos falhados, 3 -pelos cálculos de ( $\beta$ conhecidos comparados às curvas de subsidência obtidas por backstripping, 4 pelo balanceamento de áreas e por outros métodos. Para a Bacia Sanfranciscana, uma estimativa, considerando a espessura da seção cretácea inferior e o rejeito dos falhamentos, indica valores de referência inferiores a 1,3 , ou seja, extensões menores que $30 \%$. Na porção norte da bacia, para um mesmo intervalo de tempo, o valor de $\beta$ foi ainda menor. A ausência total de evidências de associação magmática (rochas vulcânicas e diques) também corrobora esta estimativa do valor de estiramento crustal. $\mathrm{O}$ registro de magmatismo se inicia quando os valores de extensão superam $400 \%(\beta=4)$.

Esta fase de evolução tectônica na porção meridional da bacia, embora com pequena magnitude, caracteriza o primeiro registro de subsidência mecânica da bacia, tendo sido responsável pela geração da depressão do Abaeté que recebeu os sedimentos do Grupo Areado.

Na porção setentrional, por ter sido uma região submetida a um campo trativo de menor proporção, ocorreu apenas a reativação de estruturas locais, não ocorrendo o desenvolvimento de uma calha com características tafrogênicas. Neste segmento da bacia, esta fase foi responsável por uma subsidência incipiente de comportamento flexural causada por um pequeno estiramento crustal. Este processo se desenvolveu a partir da resposta elástica da litosfera continental submetida a tensões (Karner et al. 1983).

A origem da depressão do Abaeté foi iniciada a partir da reativaçẫo dos lineamentos proterozóicos presentes no embasamento, como já reconhecido por Hasui \& Haralyi (1991) e Sawasato (1995). Os mecanismos de reativação normal de planos de fraqueza pré-existentes foram discutidos por Supe (1985), Magnavita (1993) e Sawasato (1995). Os principais parâmetros, que controlam o comportamento da deformação sobre um substrato com anisotropias, estão abaixo listados:

- um número de planos de falhas/fraturas, maior que o teoricamente esperado, geralmente é produzido;

- as tensões necessárias para provocar a ruptura são menores que as requeridas para desenvolver fraturas/faIhamentos em corpos homogéneos;

- o ângulo entre o plano de mergulho das anisotropias e o esforço principal máximo $\left(\sigma_{1}\right)$ influi diretamente na potencialidade de reativação, de forma que quanto maior seu mergulho, maior seu potencial de reativação. Geralmente, ângulos menores que $30^{\circ}$ favorecem a reativação de planos existentes (Fig.4)

- o ângulo entre a direção das anisotropias e o esforço mínimo $\left(\sigma_{3}\right)$ também é um fator determinante para a reativação normal. Ângulos maiores que $60^{\circ}$ favorecem a reativação dos planos pré-existentes, enquanto ângulos menores determinam o desenvolvimento de novos planos (Fig. 4).

- o comportamento reológico do substrato também é um fator importante. Existe uma tendência de reativação de diversos planos em embasamentos mais rúpteis (e.g. graníticos) e apenas das principais descontinuidades nos embasamentos mais plásticos (e.g. xistos).

No caso da Depressão do Abaeté, a reativação dos principais lineamentos proterozóicos foi favorecida, pois estes são, de forma geral, quase ortogonais à direção da extensão máxima ( $\sigma_{1}$ aproximadamente vertical). A direção das estruturas pode ser observada na figura $2 \mathrm{ou}$, em maior detalhe, em Hasui \& Haralyi (1991).

Para a geração da depressão, além do ângulo entre extensão e descontinuidades favoráveis, também foi relevante o fato da maior parte das anisotropias ser representada por falhas de alto 

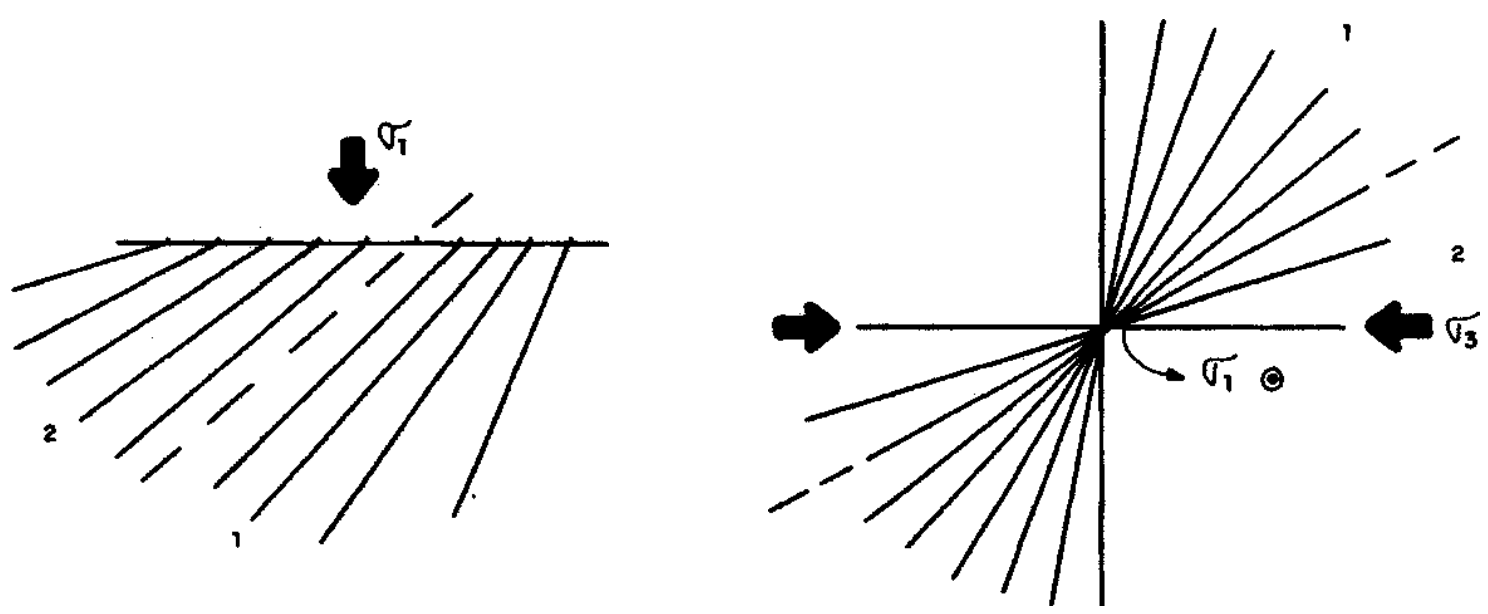

Figura 4 - $\boldsymbol{A}=$ relação angular entre a direção do esforço máximo e o mergulho das anisotropias. $\boldsymbol{B}$ - relação angular entre a direção da extensão máxima e a direção do plano das anisotropias. A região l indica a condição que favorece a reativação dos planos de fraqueza. Na região 2 existe a tendência de geração de novos planos e não reativação dos planos de fraqueza herdados. Figure $4-\mathbf{A}=$ angular relation between the maximum stress direction and the dipping of the anisotropies. $\mathbf{B}=$ angular relation between de raaximum extension direction and the anisotropies plane direction. The region 1 indicates the condition that favours the reactivation of the weakness planes. In the region 2 there is a trend to generates new planes instead of reactivate weakness planes.

ângulo. Embora a cinemática das estruturas do embasamento na região da depressão do Abaeté ainda não seja totalmente conhecida, trabalhos mais recentes desenvolvidos em setores diferentes da falha de João Pinheiro (uma das mais importantes do contexto da bacia) indicam se tratar de uma falha transcorrente (Pinho \& Dardenne, 1994) ou uma falha inversa de alto ângulo (Bacelar, 1989).

Sawasato (1995), a partir de detalhado estudo altimétrico da discordância basal (contato entre o Grupo Bambuí e a Formação Abaeté), ao longo da falha de João Pinheiro, colocou em evidência as principais características das bacias extensionais, como basculamento e rotação de blocos entre falhas, rejeitos da ordem de 100 metros junto aos depocentros, escalonamentos de blocos e fraturas de tracão.

As direções das falhas de pequeno rejeito, que afetam os sedimentos do Grupo Areado, principalmente em sua seção basal, são bastante coerentes com as direções dos lineamentos do embasamento, inclusive mudando sua direção quando ocorrem inflexões das estruturas herdadas.

$\mathrm{Na}$ Depressão de Urucuia, a maior parte da tensão trativa foi possivelmente acomodada por um pequeno estiramento crustal, provocando reduzida subsidência regional. Este fato se deve à ausência de descontinuidades expressivas no interior do cráton e à pequena distensão a qual a placa foi submetida. $\mathrm{O}$ amplo predomínio de rochas pelíticas pode ser também considerado como um fator secundário contribuindo para a explicação da dissipação do stress extensivo sem a geração de fraturas/falhamentos.

Apenas localmente na Sub-Bacia Urucuia, ocorreram as condições favoráveis que permitiram a formação de pequenos grabens ligados a esta fase. Borges et al. (1990) descrevem um exemplo relacionado a esta tectônica na porcão norte da Faixa Brasília, na borda oeste da bacia, onde sobre os lineamentos N-S, N10W, N30E e N45E, impressos em terrenos granito-greenstone da região de Dianópolis - Almas/TO, desenvolveram-se hemigrabens orientados segundo as direções das anisotropias do embasamento. Nestas estruturas, acumularam-se os sedimentos fluviais do Grupo Areado.

O desenvolvimento destes grabens na Sub-Bacia Urucuia foi condicionado à presenca dos lineamentos do embasamento que, como na Sub-Bacia Abaeté, eram estruturas original- mente de alto ângulo (Borges et al. 1990) e quase ortogonais à extensão máxima. Nos setores onde não existiam anisotropias no embasamento, como por exemplo na região de Posse/GO, os sedimentos do Grupo Areado estão preservados em pequenas depressões atectônicas (paleovales) escavadas no Grupo Bambuí ou sobre os sedimentos paleozóicos.

A sucessão estratigráfica, onde se nota a quase total ausência de conglomerados acima da Formação Abaeté (com exceção nas adjacências da falha de João Pinheiro nas proximidades de Galena/MG), mostra que a tectônica formadora apresentou um grande pulso de subsidência mecânica inicial, ou seja, um rápido estágio de abatimento e posteriormente apenas reajustes de blocos.

Utilizando-se a fórmula de McKenzie (1978) para a estimativa da subsidência inicial:

$$
\mathbf{S}_{\mathbf{i}}=\frac{\mathbf{a}\left[\left(\rho_{0}-\rho_{c}\right) \mathbf{t}_{\mathbf{c}} / \mathbf{a}\left(1-\alpha \mathbf{T}_{1} \mathbf{t}_{\mathrm{c}} / \mathbf{a}\right)-\alpha \mathbf{T}_{1} \rho_{0} / 2\right](1-1 / \beta)}{\rho_{0}\left(1-\alpha \mathbf{T}_{1}\right)-\rho_{w}}
$$

onde: $\mathrm{Si}=$ subsidência inicial, $\mathrm{po}=$ densidade do manto a $0^{\circ} \mathrm{C}, \mathrm{p}_{\mathrm{c}}=$ densidade média da crosta a $0^{\circ} \mathrm{C}, \mathrm{p}_{\mathrm{w}}=$ densidade da água do mar, $\mathrm{oc}=$ coeficiente de expansão termal da crosta e do manto, $\left(3=\right.$ coeficiente de extensão crustal, $t_{c}=$ espessura média da crosta, $\mathrm{TI}=$ temperatura da astenosfera

Considerando uma crosta de $20 \mathrm{~km}$ de espessura na época da instalação da Sub-Bacia Abaeté associada aos parâmetros tabelados por Parsons \& Sclater (in McKenzie, 1978), a subsidência inicial para aquele setor da bacia foi da ordem de $0,108 \mathrm{~km}$, valor compatível com as espessuras e características gerais dos sedimentos nos depocentros da bacia.

A atividade tectônica sin-sedimentar é marcada pela presença frequente, mas isolada, de estruturas de deformação penecontemporâneas, interpretadas como sismitos. Este fato também é evidenciado pelas pequenas falhas normais (rejeitos centimétricos) de direções variando de $\mathrm{N} 30-40 \mathrm{~W}$ a $\mathrm{N} 30-40 \mathrm{E}$ observadas nos sedimentos dos grupos Areado e Santa Fé.

As feições gerais da sucessão sedimentar, associadas à ausência de falhas de crescimento, falhas de transferência, 
blocos altos e de vários depocentros, (as quais representam características gerais dos riftes), indicam que, apesar de terem ocorrido reativações das estruturas herdadas do embasamento, esta fase genética não representa a evolução de um rifte, mas apenas o reflexo do rifteamento que culminou com a separação gonduânica.

Indicadores cinemáticos da deformação, baseados nas atitudes das fraturas trativas e no campo de stress do contexto da ruptura do Gonduana, mostram um elipsóide de tensões com ai vertical, as (horizontal) N60-70W/S60-70E e $\sigma_{3}$ (horizontal) N20-30E/S20-30W. As concentrações máximas de atitudes das fraturas abertas, que afetam o Grupo Areado, são N60E/75SE e N30W/85SW, as quais concordam com o elipsóide de tensões proposto.

ESTÁGIO TECTÔNICO CENOMANIANO (MesoNeocretáceo) Corresponde ao estágio que marca a passagem da fase rifte para a fase pós-rifte na margem continental com a consequente geração de assoalho oceânico durante a fase de mar aberto (época de deposição da megasseqüência marinha). Neste estágio ocorreu a inversão do campo de tensão, que passou de extensivo a compressivo no interior das placas sul americana e africana.

Zoback et al. (1989), a partir de medidas globais de stress, efetuadas por meio de variações de diâmetro de poços, mecanismos focais de terremotos e diques quaternários, mostraram que, no interior da placa sul americana, a tensão compressional máxima é paralela à direção das falhas transformantes (aproximadamente E-W). Assumpção et al. (1985), a partir de estudos de mecanismos focais de terremotos, obtiveram o mesmo resultado. Essa direção, atribuída ao ai, deve ter sido mantida desde os tempos albianos, pois a placa sul americana não sofreu rotação significativa durante sua migração e esteve situada sempre entre a zona de convergência andina (contexto geotectônico compressivo) e a cadeia meso atlântica (contexto geotectônico distensivo), que geram esforços diametralmente opostos.

Karner (1986) modelou e mostrou, a partir de argumentos matemáticos (teoria elástica) e geológicos (relação de onlap nas bordas das bacias intracratônicas), que a litosfera continental pode sofrer subsidência ou soerguimento quando submetida a tensões intraplaca (lithospheric in-plane stress). As conclusões de Karner (1986) e Karner et al (1983) indicam que uma bacia sedimentar desenvolvida sobre placa continental, em regime extensivo, sofre soerguimento na porção central e subsidência na porção lateral. Quando sob compressão, responde com subsidência central e soerguimento nas bordas da bacia. A magnitude do movimento vertical é função da magnitude do esforço, da espessura elástica da placa e do seu comportamento térmico, atingindo facilmente várias dezenas de metros no caso de litosfera submetida a poucos kilobares de tensão compressiva (equivalente ao peso da pilha sedimentar que gera subsidência flexural por carga -Cloetingh et al. 1985).

Dessa forma, esta fase da evolução da Bacia Sanfranciscana foi marcada pela subsidência originada pela compressão a qual o Cráton foi submetido após a fase rifte, conforme hipótese já considerada por Chang et al. (1992). Neste caso, as tensões intra-placa seriam responsáveis pelo aumento da subsidência flexural gerada na fase anterior, principalmente na Sub-Bacia Urucuia.

As bordas da bacia, que sofreram soerguimento, apresentavam pequenas espessuras de sedimentos e correspondiam as porções atualmente erodidas ao longo da Serra Geral de Goiás (a oeste) e ao longo do Vale do Rio São Francisco (a leste).

Este estágio formador da bacia, embora aparente uma fase tectônica pouco enérgica, com pequena subsidência de caráter flexural, foi responsável pela formação da depressão onde se acumulou o maior volume de sedimentos na Bacia Sanfranciscana, correspondente à Sub-Bacia Urucuia.

O caráter da superficie, que separa a sucessão fanerozóica do Grupo Bambuí, caracterizada por uma discordância regional e muito regular, também está de acordo com a compensação isostática regional, que é o tipo de compensação relacionada a este tipo de evolução (Karner, 1986). A compensação isostática local é mais comum nas fases com subsidência mecânica pronunciada.

Este mesmo estágio foi responsável, na Sub-Bacia Abaeté, pela reativação inversa de falhas normais geradas no estágio anterior. Estas falhas inversas ocorrem com certa frequência em toda a porção sul da bacia, sendo caracterizadas por pequenos rejeitos (centímetros a $3 \mathrm{~m}$ ) e acomodando a fase inicial de mudança do campo tensional, ou seja, imediatamente após a total abertura oceânica e início de geração do assoalho oceânico. Na região de Santa Fé de Minas/MG, existem exemplos destas falhas cortando a base do Grupo Santa Fé. No Triângulo Mineiro, as mesmas são comumente observadas cortando a base do Grupo Areado. Um ótimo exemplo deste tipo de estrutura está representado na rodovia entre Patos de Minas e Presidente Olegário, próximo a ponte do Ribeirão da Mata, onde os sedimentos pelíticos da Formação Quiricó são afetados por uma falha de rejeito inverso de cerca de $3 \mathrm{~m}$.

Reflexos de reativação por compressão durante a fase pós-rifte da evolução das bacias da margem continental são registrados em algumas bacias costeiras brasileiras (e.g. Cremonini 1995, estudando a evolução da Bacia Potiguar).

ESTÁGIO TECTÔNICO C AM P AN I AN O - MAASTRICHTIANO (Neocretáceo) Corresponde a fase denominada margem passiva da evolução das bacias costeiras. Durante este episódio, o mecanismo de expansão contínua do fundo oceânico, com o desenvolvimento das fraturas transformantes associadas, se implantou definitivamente.

Este estágio foi particularmente ativo no extremo sul da bacia, onde o reflexo das falhas transformantes da margem continental no interior do continente se traduz na forma de faixas transcorrentes, induzindo a formação de pequenas bacias transtrativas do tipo pull apart. A influência das falhas oceânicas no interior do continente já foi assinalada por diversos autores (e.g. Asmus 1978).

A instalação de um campo de tensores extensivos NE - S W foi necessária para a implantação do magmatismo neocretáceo da Bacia Sanfranciscana, pois toda a distribuição dos diques, das rochas vulcânicas e do alinhamento de diatremas ocorre segundo faixas de direção N50-60W. A única forma de se obter um arranjo distensivo NE - SW para a porção sul da bacia é através da atuação de faixas transtrativas com a eventual geração de grabens. Estas depressões são resultantes dos esforços oriundos da extensão por rotação das placas em torno dos pólos de abertura e propagação da energia das falhas transformantes em zonas de fraqueza do embasamento para o interior do continente. Admite-se que tenha ocorrido uma refração das direções gerais das falhas transformantes (de aproximadamente este-oeste na litosfera oceânica para N50$60 \mathrm{~W}$ na litosfera continental). Esta refração ocorreu quando as falhas transformantes alcançavam um meio com contrastes de densidade, representado pela crosta continental. As descontinuidades associadas também desempenharam papel importante na localização das zonas transtrativas no interior da litosfera continental.

A hipótese proposta pode ser sustentada por diversos parâmetros. Contudo, alguns dados não são disponíveis devido ao fato das rochas vulcânicas (Formação Patos) e seu produto erosivo (Formação Capacete) recobrirem grande parte das feições tectônicas que marcam esta estruturação, dificultando a proposição de um modelo mais genérico. En- 
tretanto, várias características desta fase evolutiva são reconhecidas por Sawasato (1995). Os argumentos principais da atuação da tectônica transtrativa estão abaixo listados:

- presença de grabens de direção geral N60 - 70 W, preenchidos por sedimentos do Grupo Mata da Corda. A seção entre Presidente Olegário e Patos de Minas ilustra a existência destas estruturas, onde as espessuras máximas de lavas e tufos ocorrem no vale do Ribeirão da Mata, tornando-se mais delgadas para NE e SW (figura 5). Devido ao fato da ocorrência de rochas vulcânicas e vulcanoclásticas ser amplamente distribuída (e.g. regiões de São Gotardo e de Carmo do Paranaíba/MG), é provável que ocorram outros grabens semelhantes, paralelos a esta direção;

- falhas e diáclases de direção geral NE, que cortam os sedimentos do Grupo Areado, são descritas por Sawasato (1995) como a "tectônica modificadora da bacia". Nos afloramentos, a observação de estruturas en echelon, características deste tipo de tectônica (Sylvester \& Smith, 1976), é relativamente frequente;

- presença de pequenas estruturas em flor esporadicamente observadas, afetando os arenitos do Grupo Areado. Belos exemplos, em pequena escala, deste tipo de estrutura podem ser observados na estrada Areado - Pindaíbas e na estrada de ligação entre Areado e a BR - 365;

- presença de barras de arenitos calcíferos, exibindo estrias longitudinais e fraturas transversais escalonadas, de direção geral N50W.

- presença de falhas antitéticas.

A movimentação de blocos, um dos critérios utilizados para reconhecimento de feições transcorrentes (Zálan, 1986 a e b), no caso da Bacia Sanfranciscana, deve ter sido pouco pronunciada, com movimentação lateral de pequena amplitude. A evolução abortada da zona de cisalhamento não permitiu o desenvolvimento de falhas inversas, dobras e pares de transcorrências, tipo Riedel e anti-Riedel, características da tectônica transtrativa.

As falhas principais atingiram grandes profundidades, sendo responsáveis pela condução dos magmas explosivos que preencheram as depressões nas zonas de transtensão. A geração dos líquidos magmáticos foi facilitada pela diminuição de pressão (Bailey, 1974). A despressurização crustal, neste caso, foi causada pela faixa submetida a movimentos verticais positivos, correspondente à área do Soerguimento do Alto Paranaíba, que deve ter sido acompanhada de subida da astenosfera.

Zonas de fraqueza no embasamento, como durante a evolução Aptiana, devem ter também influenciado o desenvolvimento e a localização das faixas transtensionais.

Um exemplo, que representa em menor escala este evento tectônico, foi descrito por Saadi et al. (1991a) no sul do estado de Minas Gerais, entre os municípios de Oliveira e Santo Antônio do Amparo. A estrutura é representada por um graben de direção $\mathrm{N} 50 \mathrm{~W}$, com cerca de $10 \times 1$ km de dimensão média, preenchido por sedimentos fluviais grossos a finos (conglomerados com seixos subarredondados, arenitos e lamitos) e rochas piroclásticas alcalinas (similares às do Grupo Mata da Corda). Do ponto de vista estrutural, são registrados todos os parâmetros para a definição da tectônica transtensiva, como falhas de borda do graben, falhas inversas, falhas transcorrentes de Riedel e anti-Riedel, além de diáciases transtrativas. As feições, que marcam a tectônica geradora do graben, são facilmente observáveis, pois o mesmo ocorre encaixado em gnaisses e granitos do Complexo Barbacena, sendo apenas sua raiz preservada da erosão, que eliminou parte dos sedimentos mais jovens.

$\mathrm{Na}$ Bacia Sanfranciscana as rochas epiclásticas da Formação Capacete, cujas áreas de ocorrência ultrapassam os limites dos grabens, recobrem grande parte das feições tectônicas associadas.

ESTÁGIO TECTÔNICO TERCIÁRIO Corresponde à fase de reativação neotectônica registrada por toda a bacia, especialmente na sua porção setentrional, onde um padrão de drenagem retangular é bem marcado em qualquer escala de observação menor que 1:100.000.

O termo "neotectônica", como por referido por Hasui (1990), será utilizado neste trabalho como a tectônica ressurgente, que atua desde o Terciário. Este conceito é mais amplo que a proposição de Mörner (1993), o qual restringe esta designação para os fenômenos tectônicos globais ocorridos no curto período correspondente aos últimos 2,5 a 3,0 Ma, isto é, restritos ao Quaternário.

Este estágio foi importante, pois condicionou grande parte do sistema de drenagem atual, como já mostrado por Saadi et al. (1991b) na porção sul da bacia. Na região norte, o sistema
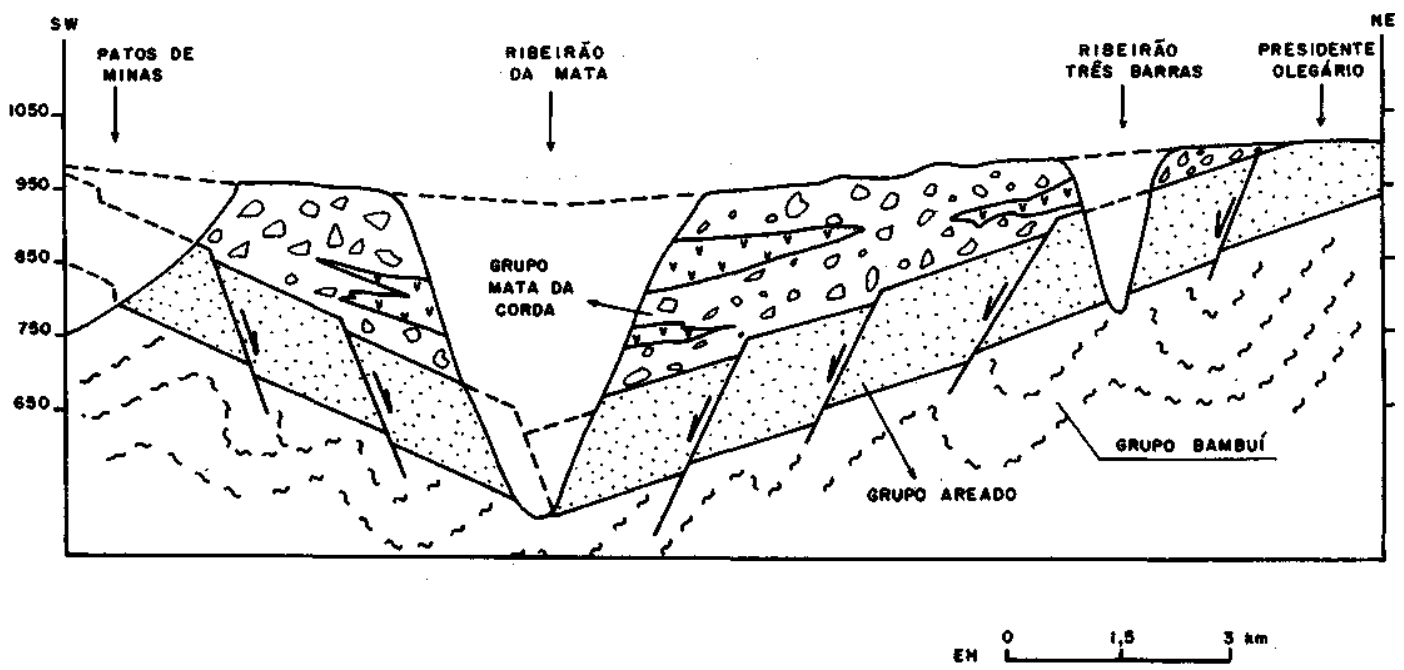

Figura 5 - Seção esquemática mostrando a variação de espessura das rochas vulcânicas e sedimentos epiclásticos do Grupo Mata da Corda entre Patos de Minas e Presidente Olegário em Minas Gerais. A estruturação do graben é ortogonal à seção com direção geral $N 50 \mathrm{~W}-60 \mathrm{~W}$.

Figure 5 - Schematic section showing the thickness variation of the volcanics and epiclastic sedimente of the Mata da Corda Group between Patos de Minas and Presidente Olegário in the Minas Gerais State. The graben structuration is orthogonal to the section, showing N50 - 60W trends. 
retangular de drenagem de baixa densidade $\left(0,1\right.$ a $\left.0,2 \mathrm{~km} / \mathrm{km}^{2}\right)$ foi condicionado pela alta capacidade de infiltração dos arenitos do Grupo Urucuia e pela cobertura arenosa residual da Formação Chapadão.

Como para os outros estágios da evolução da bacia, foram importantes as zonas de fraqueza existentes no embasamento, para a reativação neotectônica. A incipiente magnitude dos esforços provocou apenas um fraturamento espaçado ou falhamentos com pequenos rejeitos normais (não superiores a $10-15 \mathrm{~m})$.

Esta reativação foi resultante de pequena movimentação, principalmente do fraturamento N50-60E, bem representado no Grupo Bambuí, sob um campo compressivo com 01 equatorial. Neste sistema, as fraturas reativadas correspondem a fraturas de cisalhamento, sendo seu par conjugado menos desenvolvido, pois esta direção não apresenta um padrão nítido no embasamento.

A sequência de figuras, de $6 \mathrm{~A}$ a $6 \mathrm{~F}$, sintetiza esquematicamente a génese e evolução tectônica da bacia.

EVOLUÇÃO PALEOGEOGRÁFICA A evolução paleogeográfica da Bacia Sanfranciscana foi fortemente controlada pelos estágios tectônicos que condicionaram os períodos de deposição e de erosão. O balanço deposição/erosão foi responsável pelo desenvolvimento de três grandes descontinuidades reconhecíveis por toda a extensão da bacia.

A primeira superfície limitante é representada por uma discordância erosiva, localmente angular que separa os estratos glaciogênicos neopaleozóicos das rochas do embasamento. Após o término da sedimentação do Grupo Santa Fé, todo o pacote foi submetido a sucessivos retrabalhamentos, atuantes principalmente no início do Mesozóico, em resposta aos reequilíbrios isostáticos pós-glaciais. A preservação de sedimentos do Grupo Santa Fé foi possibilitada em função de presença de depressões no embasamento, em grande parte resultantes da geomorfologia glacial. A distribuiçã̃o das fácies glaciais e sua relação com exposições do embasamento mostra que o paleo relevo à época glacial foi arrasado, contudo preservando áreas elevadas isoladas.

A segunda descontinuidade importante é representada pela superficie que separa as unidades do Cretáceo Inferior (formações Abaeté, Quiricó e Três Barras) do Grupo Santa Fé e do embasamento. É representada por uma discordância erosiva e localmente angular. Na Sub-Bacia Abaeté esta superfície é irregular, apresentando topografia com desníveis de até $100 \mathrm{~m}$, sendo condicionada pelas falhas precursoras desta sub-bacia. Na Sub-Bacia Urucuia e no Alto do Paracatu, esta discordância é representada por um plano mais regular, sendo apenas mais escavada sobre os sedimentos glaciais, onde a Formação Abaeté pode alcançar dezenas de metros de espessura.

A terceira importante superfície limita as unidades do Cretáceo Superior de todas as unidades mais antigas da bacia. Representa uma discordância erosiva e localmente paralela. Esta superficie limitante pode ser dividida em dois segmentos: um no extremo sul da Sub-Bacia Abaeté e outro no resto da bacia. A Figura 7 mostra de forma comparada a evolução das bacias do Paraná e Sanfranciscana.

$\mathrm{Na}$ Sub-Bacia Abaeté, esta discordância é pouco exposta em virtude de seu recobrimento por fácies epiclásticas. Contudo seu aspecto escalonado é evidenciado pelas variações de espessura de Grupo Mata da Corda. Neste segmento, esta discordância separa as rochas vulcânicas e epiclásticas de arenitos do Grupo Areado e, apenas localmente, separa rochas epiclásticas de metapelitos do Grupo Bambuí.
Nas demais regiões da bacia, esta discordância é representada por uma superficie extremamente regular, marcando o contato do Grupo Urucuia diretamente sobre o embasamento, sobre o Grupo Santa Fé ou sobre o Grupo Areado. Apenas na região do Alto do Paracatu, existe o contato direto do Grupo Mata da Corda sobre o Grupo Urucuia, mostrando a interdigitação lateral de parte destas unidades.

Superfícies limitantes internas são observadas dentro das grandes unidades (e.g. pavimento deflacionário caracterizado pela presença de ventifactos no topo da Formação Abaeté), contudo estas descontinuidades são locais sem continuidade lateral, não podendo ser consideradas na escala da bacia.

A evolução da sedimentação no tempo, analisada a partir dos dados de paleocorrentes, apresenta o seguinte quadro:

\# Sedimentação axial no Neopaleozóico, com deposição de nordeste para sudoeste a partir do Espinhaço Setentrional;

\# Sedimentação transversal no Eocretáceo, com áreas fontes localizadas nas bordas elevadas da bacia. De sul para norte, a partir da região soerguida do Alto Paranaíba, aproximadamente de oeste para leste a partir da Faixa Brasília (regiões de Brasilândia e Garapuava), e de leste para oeste a partir da Serra do Cabral;

\# Novamente sedimentação axial no Neocretáceo, com desenvolvimento da sedimentação Mata da Corda a partir dos centros vulcânicos localizados no extremo sul da bacia e deposição eólica do Grupo Urucuia de nordeste para sudoeste a partir da Cordilheira do Espinhaço Setentrional.

CONCLUSÕES A origem da bacia foi marcada por uma evolução que, de forma geral, envolveu pequenas taxas de deformação. Á subsidência que gerou a calha sedimentar foi produzida por reequilíbrios isostáticos, extensão e compressão crustais, ligados à glaciação neopaleozóica e à ruptura gonduânica. Seis estágios sintetizam os processos envolvidos na sua origem e evolução tectônica: Paleozóico - fase de tectônica pouco pronunciada, onde a calha sedimentar era representada por um "baixo relativo" entre as faixas Brasília e Araçuaí/Espinhaço Setentrional; Eomesozóico - fase de reequilíbrios isostáticos pós-glaciais; Eocretáceo -corresponde à fase extensiva relacionada a abertura sul-atlântica, este estágio foi responsável pela geração da Sub-Bacia Abaeté; Mesocretáceo - inversão tectônica da bacia, correspondente à fase pós-rifte da margem continental, foi responsável pela geração da Sub-Bacia Urucuia; Neocretáceo influência das falhas oceânicas em zonas de fraqueza continentais, responsável pela implantação do magmatismo alcalino da Sub-Bacia Abaeté; Cenozóico - fase neotectônica, responsável pela origem do sistema paralelo de drenagem na Sub-Bacia Urucuia.

Não existe uma correlação perfeita entre a evolução das bacias da margem continental brasileira e a Bacia Sanfranciscana.

Dados de paleocorrentes e proveniência mostram que a evolução da sedimentação foi controlada essencialmente pelas regiões elevadas adjacentes à bacia, tendo o maior volume de massa sido transportado ao longo do eixo norte-sul. No Neopaleozóico, o afluxo de massa foi de nordeste para sudoeste (S20W). No Eocretáceo, ocorreram contribuições das bordas da bacia, mas o principal transporte se deu de sul-sudoeste para norte-nordeste (N20E). A sedimentação Cretácea Superior da Formação Capacete evoluiu de sul para norte (a partir da região soerguida do Alto Paranaíba), enquanto o Grupo Urucuia apresentava áreas fontes localizadas na porção nordeste do Cráton do São Francisco, com sedimentação de NE para SW. 
Figura $6 A$ - Estágio tectônico $\mathrm{Pa}$ leozóico. Um baixo relativo entre duas cadeias de montanhas representou a calha que definiu a Proto Bacia Sanfranciscana. As cadeias de montanhas (faixas Brasília, Araçuaí e Espinhaço Setentrional) foram soerguidas durante o ciclo brasiliano. Os sedimentos glaciais se depositaram ao longo da porção central desta calha.

Figure 6A - Paleozoic tectonic stage. A relative low between two mountains range represented the trough that defmed the Sanfranciscana Protobasin. The mountain ranges (Brasília, Araçuaí and Northern Espinhaço belts) were raised during the brasiliano cycle. The glacial sediments deposited the central portion of this trough. Figura 6B - Estágio tectônico Neopaleozóico/Eomesozóico. Corresponde a importantes reequilibrios isostáticos pós-glaciais. Os soerguimentos regionais foram responsáveis pelo intenso retrabalhamento dos sedimentos depositados no Paleozóico. O tamanho dos círculos é proporcional à magnitude do soerguimento.

Figure 6B - Neopaleozoic/Eomesozoic tectonic stage. It corresponds to important post glacial reequilibration. The regional uplift was responsible for intense reworking of the sediments deposited in the Paleozoic. The circle size indicates the uplift magnitude.

Figura 6C - Estágio tectônico Barremiano/Aptiano. Corresponde à fase principal de estiramento crustal da ruptura gonduânica. No segmento sul, este processo reativou estruturas brasilianas presentes no emba-samento, enquanto na porção norte a dissipação do stress se deu no domínio elástico não desenvolvendo efeitos tafrogênicos. A dimenssão das setas indica a magnitude da extensão. Figure 6C - Barremian/Aptian tectonic stage. It corresponds to the main stretching phase of the Gondwana drift. In southern portion this process reactivated neoproterozoic lineaments present in the basement, while in the northern portion the energy dissipation was in the elastic domain and do not developed tafrogenic structures.
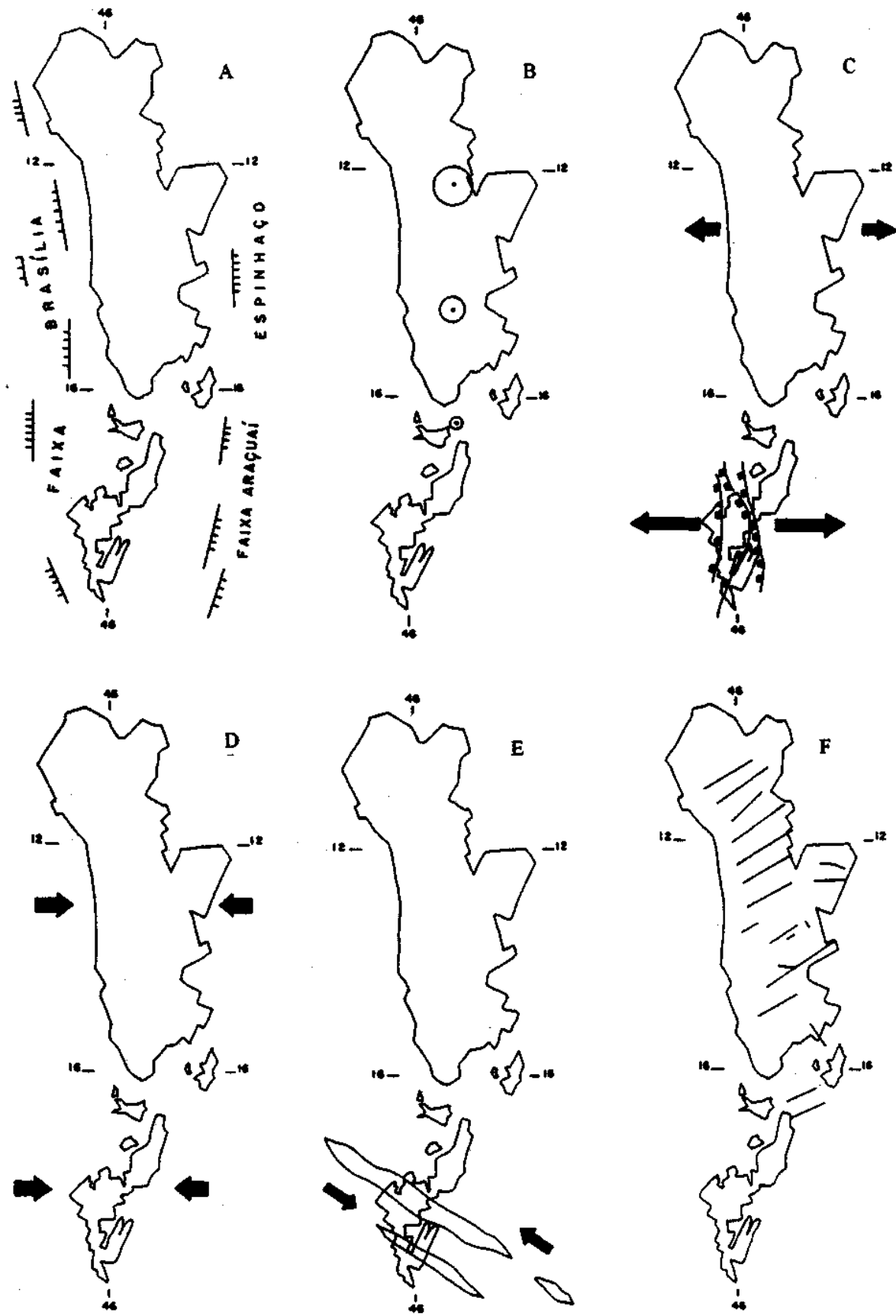

Figura 6D - Estágio tectônico Albo/Cenomaniano. Equivalente à fase pós-rifte da margem continental Este evento foi responsável pela inversão do campo de tensões que passou de extensivo a compressivo. A atuação de tensões intra-placa amplificou a subsidência flexural, sendo responsável pela criação da grande calha rasa na qual se depositou o Grupo Urucuia.

Figure 6D - Albian/Cenomanian tectonic phase. This phase is equivalent to the South Atlantic post rift stage. This tectonic event was responsible for the compressive stress field inversion. The activity of in-plane stress magnified the flexural subsidence, creating the great trough where the Urucuia Group was deposited. Figura 6E - Estágio tectônico Campaniano/Maastríchtiano. Apenas registrado na Sub-Bacia Abaeté. Se desenvolveu a partir da atuação das falhas transformantes no início da formação do assoalho oceânico, na fase de mar aberto da margem continental. Este estágio foi responsável pelo desenvolvimento de grabens e pela implantação do magmatismo relacionado ao Grupo Mata da Corda.

Figure 6E - Campanian/Maastrichtian tectonic stage, observed only in the Abaeté Sub-Basin. It developed after the activity of the transform faults in the beginning of the oceanic floor generation in the open sea phase, of the South Atlantic evolution. This stage was responsible for the development of grabens and alkaline magmatism in the Mata da Corda Group.

Figura $6 F$ - Estágio tectônico Terciário. Esta fase é caracterizada pela reativação neotectônica da bacia, produzindo um padrão retangular de drenagens (muito bem representado na Sub-Bacia Urucuia). As estruturas reativadas são bem desenvolvidas no embasamento, sendo sua geração resultado da atuação de um elipsóide de tensão com esforço máximo compressivo aproximadamente equatorial.

Figure $6 \mathrm{~F}$ - Tertiary tectonic stage. This phase is characterized by the neotectonic reactivation of the basin, producing a retangular dranaige pattern (evident in the Urucuia Sub-Basin). The reactivated structures are well developed in the basement, and were originated by an equatorial stress elipsoid. 

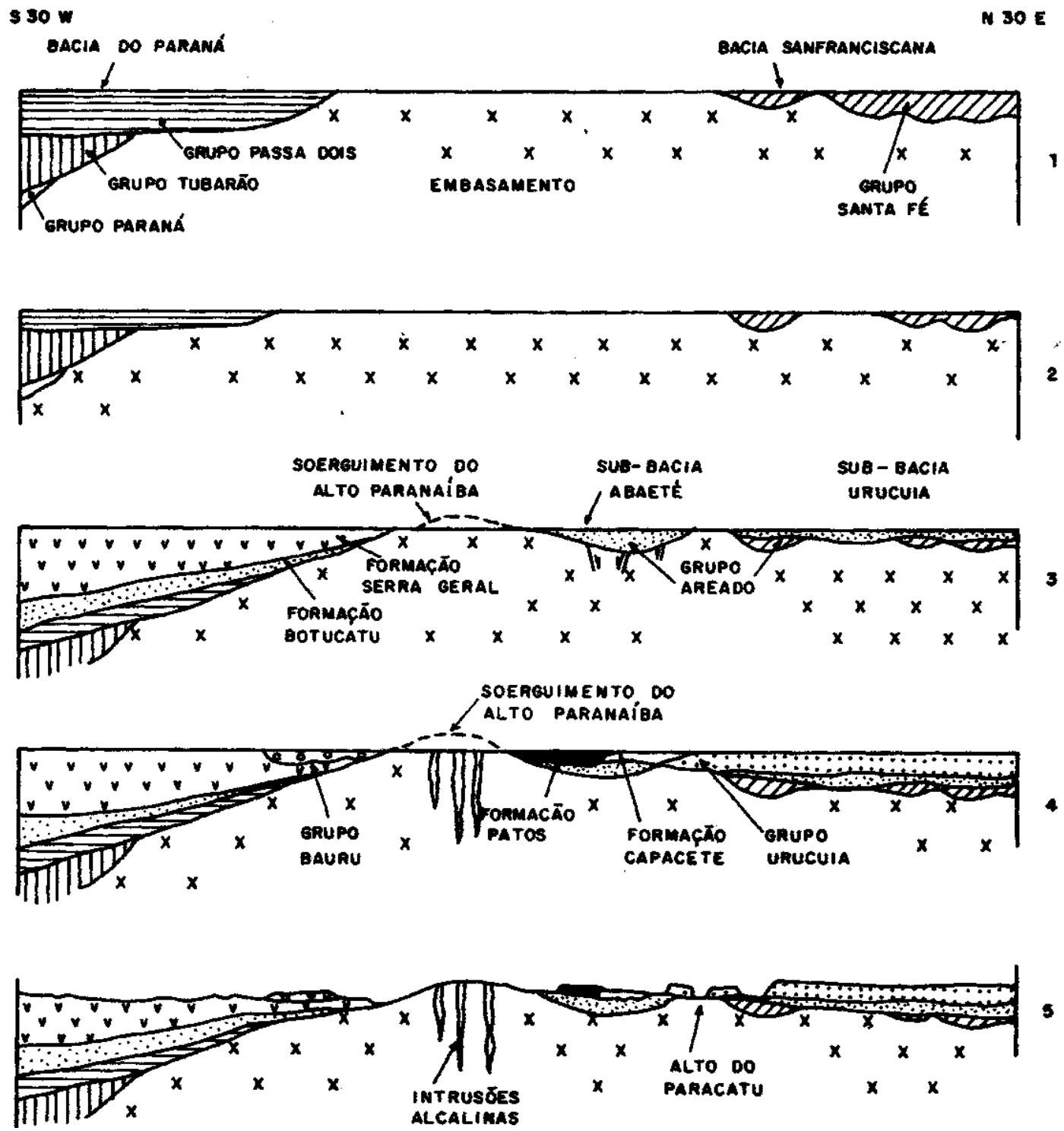

Figura 7 - Evolução paleogeográfica regional da Bacia Sanfranciscana. l Neopaleozóico - deposição do Grupo Santa Fé a partir do norte da bacia. 2 Eomesozóico -intensos processos erosivos são responsáveis pelo retrabalhamento de grande parte da sucessão Santa Fé. 3 Eocretáceo - deposição do Grupo Areado e desenvolvimento de feições tafrogenéticas na Sub-Bacia Abaeté. Início do soerguimento do Alto Paranaíba. 4 Neocretáceo - fase principal do Soerguimento do Alto Paranaíba. Deposição do Grupo Urucuia e desenvolvimento do magmatismo alcalino na área afetada pelo soerguimento. 5 Cenozóico - Acumulação da Formação Chapadão, desenvolvimento da atual superficie de relevo e incisão das formas geomorfológicas de mesetas e extensas chapadas. (Modificado de Hasui \& Haraliy 1991).

Figure 7 - Regional palaeogeographic evolution of the Sanfranciscana Basin. 1 Late Paleozoic - Santa Fé Group deposition from the north portion of the basin. 2 Early Mesozoic - intense erosive processes reworked the Santa Fé Group. 3 Early Cretaceous - Grupo Areado deposition and development of tafrogenic features in the Areado Sub-Basin. Beginning of the Alto Paranaíba uplift. 4 Late Cretaceous - main phase of the Alto Paranaíba uplift. Deposition of the Urucuia Group and alkaline magmatism in the uplifted area. 5 Cenozoic - Acumulation of the Chapadão Formation, and onset of the present geomorphological surface and incision of the mesas and plateau land forms (Modified from Hasui \& Haraliy 1991).

\section{REFERENCIAS}

Alkmin, F.F.; Chemale, F.; Bacellar, L.A.P.; Oliveira, J.R.P. \& Magalhães, P.M. 1989. Arcabouço estrutural da porção sul da Bacia do São Francisco. In: Simpósio de Geologia de Minas Gerais, 5. Anais...Belo Horizonte, SBG. 281288.

Aragão, M.A.N.F. 1994. Arquitetura, estilos tectônicos e evolução da Bacia do Recôncavo, Brasil. In: Simp. sobre o Cretáceo do Brasil, 3. Boletim...... Rio Claro. SBG. p. 165-167.
Aragão, M.A.N.F. \& Perano, A.A. 1994. Elementos estruturais do rifte Tucano/Jatobá. In: Simpósio sobre o Cretáceo do Brasil, 3. Boletim...... Rio Claro. SBG. p. 161-164.

Asmus, H,E. \& Porto, R. 1980. Diferenças nos estágios iniciais da evolução da margem continental brasileira: Possíveis causas e implicações. In: Congresso Brasileiro de Geologia, 31. Camboriú, 1980. Anais...Camboriú. SBG. p. 225-239. 
Asmus, H.E. 1978. Hipóteses sobre a origem dos sistemas de zonas de fratura oceânicas/ alinhamentos continentais que ocorrem nas regiões sudeste e sul do Brasil. In: Projeto REMAC, no. 4. Petrobrás. Rio de Janeiro. p. 39-75.

Assumpção, M.; Suarez, G. \& Veloso, J.A.V. 1985. Fault plane Solutions of intraplate earthquakes in Brazil: some constraints on the regional stress field. Tectonophysiscs, 113:283-293.

Bacellar, L.A.P. 1989. Geologia estrutural do Supergrupo São Francisco ao longo da seção regional Coromandel-Três Marias-Conselheiro Mata, M.G. UFOP Dissertação de Mestrado (inédita). Ouro Preto, 129p.

Bailey, D.R. 1974. Continental rifting and alkaline magmatism. In: Sorensen,

H. (Ed.). The Alkaline Rocks. John Willey \& Sons. New York. p.

148-159.

Bizzi, L.A.; De Wit, M.J.; Smith, C.B. \& Armstrong, R.A. 1993. Características isotópicas e origem dos kimberlitos e vulcânicas alcalinas relacionadas em Minas Gerais. In: Simpósio Brasileiro sobre a Geologia do Diamente, Brasil. Geol. Diamante. 1. Anais...Cuiabá. UFMT Publ. Esp. 2/93. p. 141-151.

Bizzi, L.A.; Smith, C.B.; Meyer, H.O.H.; Armstrong, R. \& De Wit, MJ. 1991 Mesozoic kimberlites and related rocks in southwestern São Francisco Craton, Brazil: A case for local mantle reservoirs and their interaction. Sth International Kimberlite Conference. Extended Astracts. Brazil. p. 17-19.

Borges, M.S.; Igreja, H.L.S.; Costa, J.B.S. \& Hasui, Y. 1990. Investigações tectônicas no Mesozóico do estado do Tocantins: Formação Urucuia. In: Simpósio sobre o Cretáceo do Brasil, 1. Boletim...... Rio Claro. SBG. p. 25-26.

Brown, L.D. \& Reilinger, R.E. 1986. Epeirogenic and intraplate movements. Active Tectonics, Studies in Geophysiscs, National Academic Press, Washington DC. p. 30-44.

Chang ,H.K.; Bender, A.A \& Kowsmann, R.O. 1992. O papel das tensões intraplaca na evolução de bacias sedimentares: exemplo da Formação Urucuia. In: Congresso Brasileiro de Geologia, 37. São Paulo, 1992. Anais...São Paulo, SBG. Vol. 2,. 568 e 569.

Chang, H.K. \& Kowsmann, R.O. 1991. Significado dos diques do arco de Ponta Grossa na abertura diferencial do Atlântico sul. In: Simpósio Nacional de Estudos Tectônicos, 3, Boletim Resumos Expandidos.... Rio Claro. SBG. p77-78.

Chang, H.K.; Kowsmann, R.O. \& Figueiredo, A.M.F. 1990. Novos conceitos sobre o desenvolvimento das bacias marginais do leste brasileiro. In: Raja Gabaglia, G.P. \& Milani, E.J. (Coord.). Origem e evolução de bacias brasileiras. Petrobrás Rio de Janeiro, p. 269-289.

Cloething, S.; McQueen, G. \& Lamberk, K. 1985. On a tectonic mechanism for regional sea level variations. Earth \& Plan. Sc. Letters, 75:157-166.

Costa, M.T. 1963. Estrutura geológica dos cerrados. Departamento de Pesquisas e experiências Agropecuárias, MIN. AGRIC, Bol. 15.

Cremonini, O.A. 1995. A reativação tectonica da Bacia Potiguar no Cretáceo Superior. In Simpósio Nacional de Estudos Tectônicos, 5, Gramado, SBG, p.277-280.

D'Arrigo, H.B.P. \& Alkmin, F.F. 1995. O Alto de Sete Lagoas e sua reativação. In Simpósio Nacional de Estudos Tectônicos, 5, Gramado. SBG. p.21-22.

Gibbs, A.D. 1984. Structural evolution of extensional basin margins. Jour. Geol. Socie. London, 141:1137-1152.

Hasui, Y. 1968. A Formação Uberaba. In: Congresso Brasileiro de Geologia 22. Belo Horizonte, 1968. Resumo das Comunicações. Belo Horizonte. SBG. Vol., p. 167-179.

Hasui, Y. 1990. Neotectônica e aspectos fundamentais da tectonica ressurgente no Brasil. In: $1^{\circ}$. Workshop sobre neotectônica e sedimentação Cenozóica continental no sudeste brasileiro. SBG Núcleo Minas Gerais. Belo Horizonte Boi. 11. p. 1-31.

Hasui, Y. \& Haralyi, N.L.E. 1991. Aspectos lito-estruturais e geofísicos do soerguimento do Alto Paranaíba. Geociências, São Paulo, 10:57-77.

Hasui, Y.; Sena Costa, J.B.; Borges, M.S.; Assis, J.F.P.; Pinheiro, R.V.L.; Bartorelli, A.; Pires Neto, A.G. \& Mioto, J.A. 1991. A borda sul da Bacia do Parnaíba no Mesozóico. In: Simpósio Nacional de Estudos Tectônicos. 3. Boletim Resumos Expandidos...Rio Claro. SBG. p.93-98.

Karner, G.D. 1986. Effects of lithospheric in-plane stress on sedimentary basin stratigraphy. Tectonics, 5:573-588.

Karner, G.D.; Steckler, M.S. \&Thorne, J.A. 1983.Long-term-thermo-mechanical properties of the continental lithosphere. Nature, 304:250-253.
Lesquer, A.; Almeida, F.F.M.; Davino, A.; Lachaud, J.C. \& Maillard, P. 1981. Signification structurale des anomalies gravimétriques de Ia partie sud du Craton de São Francisco (Brésil). Tectonophysics, 76:273-293.

Magalhães, L.M.; Chemale Jr, F.; Alkmin, F.F. 1989. Estilo tectônico da porção sudoeste da Bacia do São Francisco. Simpósio de Geologia de Minas Gerais, 5, Belo Horizonte, 1979. Atas...Minas Gerais, Belo Horizonte, SBG. p.284-288.

Magnavita, L.P. 1993. Reativação do embasamento pré-cambriano durante a abertura cretácea do rifte do Recôncavo-Tucano-Jatobá, NE Brasil. In: Simpósio do Craton do São Francisco, 2. Anais... Salvador. SBG. p. 227-229.

Martins, M.; Teixeira, L.B. \& Braun, O.P.G. 1993. Bacia do São Francisco: uma fronteira exploratória na pesquisa de petróleo do Brasil. In: Simpósio de Geologia de Minas Gerais, 7. Anais... Ouro Preto, SBG. p. 55-57.

McKenzie, D. 1978. Some remarks on the development of sedimentary basins. Earth and Plan. Sc. Let., 40:25-32.

Mõrner, N.A. 1993. Neotectonics, the New Global Tectonic Regime During the Last $3 \mathrm{Ma}$ and the Initiation of Ice Ages. Anais Academia brasileira de Ciências, 65:295-301.

Oliveira, J.R.P.; Alkmin, F.F \& Chemale Jr., F. 1989. Comportamento estrutural do Supergrupo São Francisco na região de Montes Claros/MG. In: Simpósio de Geologia de Minas Gerais, 5. Anais...Belo Horizonte, SBG. p. 281288.

Pinho, J.M. \& Dardenne, M. A. 1994. Comportamento da Falha João Pinheiro na região homônima, MG. In: Congresso Brasileiro de Geologia, 38. Camboriu, 1994. Boletim de Rresumos Expandidos. ...Camboriú, SBG. Vol. 1.p.249-250.

Saadi, A.; Valadão, R.C. \& Silveira, J.S. 1991a. Vulcanismo extrusivo e tectonica Cretáceos no centro-sul de Minas Gerais. In: Simpósio Nacional de Estudos Tectônicos, 3. Boletim Resumos Expandidos.... Rio Claro. SBG. p. 88-92.

Saadi, A.; Hasui, Y. \& Magalhães, F.S. 1991b. Informações sobre a neotectônica e morfogênese de Minas Gerais. In: Simpósio Nacional de Estudos Tectônicos, 3. Boletim Resumos Expandidos....Rio Claro. SBG. p. 105-106.

Sawasato, E.Y. 1995. Estruturação da porção meridional da Bacia Alto-Sanfranciscana - Cretáceo do oeste de Minas Gerais. Dissertação de Mestrado. UFOP. Ouro Preto. 127pp. (inédita).

Schobbenhaus, C.; Campos, D.A.; Derze, G.R. \& Asmus, H.E. 1984 Geologia do Brasil. Texto explicativo do mapa geológico do Brasile da área oceânica adjacente incluindo depósitos minerais (escala 7.-250.000J.MME/DNPM Brasília. 501p.

Supe, J. 1985. Principies of Structural Geology. Prentice-Hall, Inc. Englewood Cliffs.

Sylvester, A.G. \& Smith, P.R. 1976. Tectonic transpression and basement-controlled deformation in San Andreas fault zone, Salton Trough, Califórnia. AAPG Bull., 60:2081-2102.

Ussami, N. \& Sá, N.C. 1993. Digital (10' X 10') gravity maps of the São Francisco Craton and marginal fold/thrust belts. In: Simpósio do Craton do São Francisco 2. Anais... Salvador. SBG. p. 137-139.

Zálan, P.V. 1986a. A tectonica transcorrente na exploração de petróleo: uma revisão. Revista Brasileira de Geociências, 16:245-257.

Zálan, P.V. 1986b. Identificação de falhas transcorrentes em seções sísmicas. Revista Brasileira de Geociências, 16:257-265.

Zálan, P.V., Wolff, S.; Conceição, J.C.J.; Marques, A.; Astolfi, M.A.M.; Vieira, I.S.; Appi, Z.P. \& Zanotto, O.A. 1990. Bacia do Paraná. In Raja Gabaglia, G.P. \& Milani, E.J. (Coord.). Origem e evolução de bacias brasileiras. Petrobrás, Rio de Janeiro, p. 135-168.

Zoback, M.L.; Zoback, M.D.; Adams, J.; Asssmpção, M.; Bell, S.; Bergman, E.A.; Blumling, P.; Brereton, N.R.; Denham, D.; Ding, J.; Fuchs, K.; Gay, N.; Gregersen, S.; Gupta, H.K.; Gvishiani, A.; Jacob, K.; Klein R.; Knoll, P.; Magee, M.; Mercier, J.L.; Muller, B.C.; Paquin, C.; Rajendran, K.; Stephansson, O.; Suarez, G.; Suter, M.; Udias, A.; Xu, Z.H. \& Zhizhin, M. 1989. Global patterns of tectonic stress. Nature, 341:291-298

MANUSCRITO A-919

Recebido em 04 de junho de 1997

Revisã o dos autores em 20 de setembro de 1997

Revisão aceita em 10 de outubro de 1997 